Lowrie, A. \& Hemsley-Brown, J. (2011). This thing called marketisation (Editorial). Journal of Marketing Management, 27, 1081-1086.

Dr Anthony Lowrie, Professor of Marketing, Minnesota State University, Moorhead, USA.

Dr Jane Hemsley-Brown - Reader in Marketing, University of Surrey Business School, Guildford, Surrey UK

\title{
EDITORIAL
}

\section{This thing called marketisation}

Marketing and marketisation are not the same. However, it is not a simple task to disentangle one from the other. At one end of the distribution of meaning, marketing may be taken to be about the provision of information to help people make decisions while at the other end of this distribution, marketisation challenges stakeholders with radical change encompassing issues of power, funding, labour, markets and complexity. Nor is this a comprehensive list (see for example Hemsley-Brown \& Oplatka, 2006). Indeed, the idea of a definitive list is misleading. Meanings and lists tend to chop and change according to the particular perspective slicing the dialogue. While it is difficult to get an intellectual handle on what is happening with regard to marketing higher education never mind what to do about it - the reader might like to think that that is rather the point: the complexity keeps the stakeholder guessing at what is difficult, if not impossible, to predict and so this keeps us on our academic toes.

Nevertheless, there are three very important characteristics evident in the literature to describe the situation and help us to develop an intellectual understanding of 
Lowrie, A. \& Hemsley-Brown, J. (2011). This thing called marketisation (Editorial). Journal of Marketing Management, 27, 1081-1086.

marketisation: 1) higher education is characterised by plurality; 2) it is competitive and likely to get even more competitive; and 3) it is rife with contestation. More than anything else in our research into marketing and the marketisation of higher education, we need analytical concepts to deal with these highly prominent yet not all-embracing characteristics. As the complexity and diversity of the literature in the subject area suggests, this is not going to come from a single disciplinary source.

With regard to these characteristics, it is not simply a question of a variety of institutions of higher education competing, but these varied institutions are occupied by academics with competing theories. So institutional plurality and intellectual plurality add to the competitive fuel. Burning themes arising from these characteristics set within academic contestation are: increasing complexity; the rise of consumerism; rankings; the promotion of relevance; and identity. With regard to the second characteristic, it is irrelevant whether you like or approve or not; competition will define higher education and its being in the world and where that being is placed. Higher educations' identity and how stakeholders identify with it will alter radically. Indeed, it is already inaccurate to speak of the identity of higher education rather than identities. In consideration of the third set of characteristics, none of these goes unchallenged. Consensus is a long way off. The way forward is paved with many possibilities and potential directions.

The plurality and competitive characteristics have multiple implications that work their way through how we approach marketing for higher education, understand it and then deal with it. The articles in this special issue are just some of the research outcomes that 
Lowrie, A. \& Hemsley-Brown, J. (2011). This thing called marketisation (Editorial). Journal of Marketing Management, 27, 1081-1086.

link the major themes emanating from the characteristics. It would be impossible, of course, to cover all these themes in one special issue. Nevertheless, the articles in this special edition of the Journal of Marketing Management illustrate how marketing for higher education research is intricately bound up with a) the characteristics and b) the themes and c) how researchers break these themes down into manageable research topics such as marketing strategy, services marketing, consumer behaviour, and so on...

\section{Summary of articles}

This special issue comprises eight articles by researchers from Australia, India, the United Kingdom and the United States who take different positions on marketisation. The running order does not in any way reflect any aspect of quality or preference but rather thematic convenience. The articles are organised on a thematic basis with papers on strategy presented first, followed by papers on consumerism, governmentality and choice (in relation to price elasticity); the final papers relate to satisfaction, value and service quality in higher education.

Roger Bennett and Rita Kottasz point out in the first paper, that universities adopt both competitive (as opposed to co-operative) and strategic (rather than ad hoc) approaches towards internationalisation. Schools tend to either take a co-operative or a competitive approach but they rarely choose to attempt both approaches simultaneously. Marketing strategy implementation, however, especially in the context of international student recruitment remains an under-developed area in terms of the marketisation of higher education. Vik Naidoo and Terry Wu seek to address this omission in the second paper 
Lowrie, A. \& Hemsley-Brown, J. (2011). This thing called marketisation (Editorial). Journal of Marketing Management, 27, 1081-1086.

when they identify and test a conceptual model comprising factors which influence successful marketing strategy implementation for recruitment of international students. They argue that the findings support commitment factors as critical to strategic implementation with both strategic commitment and role commitment found to be positive and significant in influencing role performance.

Some authors celebrate the process of marketisation of higher education as liberating and enhancing responsibility, and see it as improving the performance of institutions that make a major contribution to the public good while others see it as a harmful process for learning and knowledge creation. Rajani Naidoo, Avi Shankar and Ekant Veer argue that the consumerist turn heralds many negative consequences. Students in the current and future higher education market have much more complex choices to make and universities are under considerable pressure to meet students' needs. Naidoo et al. raise concerns therefore about the dangers of such developments and express concerns about the socialisation of disadvantaged students in this new marketised system. They conclude that the most corrosive effects of consumption in higher education are likely to be felt more strongly in vulnerable institutions that admit students from disadvantaged backgrounds.

Varman, Saha and Skålén also raise concerns about the effects of marketisation in higher education. Their article uses 'Foucault's conceptualisation of governmentality and uncovers processes through which market subjectivity is fostered among students as they 
Lowrie, A. \& Hemsley-Brown, J. (2011). This thing called marketisation (Editorial). Journal of Marketing Management, 27, 1081-1086.

strive to become responsive, active and entrepreneurial subjects'. The research conducted by Varman et al. (a case study of one Indian business school) found that students gave priority to their own gains and uncritically celebrated neoliberalism. Findings indicate that market subjectivity results in the prevalence of instrumental rationality, failure to develop a critical academic perspective, subordination of social concerns, disenchantment and exclusion. The article offers considerable insight and understanding of student behaviour during the process of marketisation under neoliberalism in a developing country.

Pricing is one of the most contested issues confronting higher education institutions in a marketised system where students are choosing among institutions. Robert Carter and David Curry evaluate tuition elasticity in higher education and found that average elasticities vary considerably across colleges in a research university in the USA. Business and Engineering colleges (faculties) exhibit the highest level of elasticity and these differences appear to reflect differences in respective national reputations. Carter and Curry argue that, despite political risks and ethical concerns, results suggest that differential pricing at a college or faculty level is a policy instrument that needs to be seriously evaluated.

Higher education institutions are increasingly adopting commercial practices pertaining to measuring consumer satisfaction. Three papers in this special issue focus on aspects of satisfaction and service: Palmer and Koenig-Lewis explore the effects of emotions and 
Lowrie, A. \& Hemsley-Brown, J. (2011). This thing called marketisation (Editorial). Journal of Marketing Management, 27, 1081-1086.

peer group interaction on students' satisfaction; Ledden, Kalafatis and Mathioudakis explore service quality, value, and satisfaction in terms of intention to recommend an institution; and Gruber, Chowdhury and Reppel explore service recovery in higher education with a focus on national culture.

Palmer and Koenig-Lewis challenge approaches to the measurement of customer satisfaction which focus on the cognitive, rather than the affective components. Their article contributes to the higher education marketisation debate by identifying direct and indirect effects of emotions on satisfaction and behavioural intentions before consumption, which suggest that there are benefits to extending relationship building to the pre-enrolment stage. This raises the spectre of marketing to children if we take the definition of children to mean those under the age of 18 via the medium of social networks - something which, of course, already occurs and is likely to increase.

Ledden, Kalafatis and Mathioudakis argue that service quality is treated as an antecedent of value which in turn is a driver of customer satisfaction which ultimately drives word of mouth. They set out a theoretical model which incorporates the 'get' and 'give' dimensions of the value exchange. The authors point out that the implications of their findings present managers with the challenge of differentiating service to take into account different expectations and experiences according to the type of course studied. 
Lowrie, A. \& Hemsley-Brown, J. (2011). This thing called marketisation (Editorial). Journal of Marketing Management, 27, 1081-1086.

The final paper deals with a new and somewhat controversial topic in terms of services recovery in higher education. Gruber, Chowdhury and Reppel investigate how national culture influences student expectations of attributes and the desirable behaviours of professors in managing service failure. The research reveals that key attributes desired by both groups of students include being approachable, listening actively, showing empathy and providing explanations. Gruber et al. argue that the results mirror those from commercial service recovery research where customers from individualistic cultures have been found to emphasise the service's functional or transactional elements whereas those from collectivist cultures have been found to emphasise more intangible relational elements of service.

\section{Future directions}

The enhancement of a market in higher education presents some conflicts and tough decisions for those involved in the research of marketisation in higher education as well as those involved in the marketing of higher education. Authors included in this special issue offer a range of views and recommendations on the ways in which future research can make a contribution to providing insights into the dilemmas, conflicts and challenges for stakeholders.

A prominent topic for research is globalisation. Research which focuses on higher education marketing strategy and competition, has been documented in previous literature and covers a wide range of strategic approaches to marketing higher education and marketing strategy (e.g. Conway et al., 1994; Bakewell \& Gibson-Sweet, 1998; Trim, 
Lowrie, A. \& Hemsley-Brown, J. (2011). This thing called marketisation (Editorial). Journal of Marketing Management, 27, 1081-1086.

2003; Niculescu, 2006). However, Bennett \& Kottasz suggest that further research might focus on the interaction between the numbers of foreign students a university recruits and its approach to internationalisation. Palmer and Koenig-Lewis indicate that further research is needed to test their model outside the UK to investigate whether international students evoke a different set of emotions compared with those who study in their home countries.

In terms of research in internationalisation and higher education marketing, therefore, future researchers might also wish to take account of Gruber et al's suggestion that frameworks other than Hofstede's (Ng et al., 2007) could be used. They argue that other models may yield further insight into the influence of national culture and they point out a number of other possible frameworks for measuring national cultural values including Scwartz's framework (Scwartz 1994) because this approach includes elements of culture that are not captured by Hofstede (see Ng et al., 2007).

Second, in terms of neoliberal rationality and consumption there is still considerable potential in terms of markets, marketisation and higher education research. Varman et al. suggest that further research is needed to understand the role of critical pedagogy in creating greater resistance to neoliberal rationality among students. Moreover, although there is a strong body of work on critical marketing which has emerged in recent years, see Tadajewski (2010) for a history of critical marketing, there are very few critical higher education marketing articles at the institutional level as opposed to curriculum 
Lowrie, A. \& Hemsley-Brown, J. (2011). This thing called marketisation (Editorial). Journal of Marketing Management, 27, 1081-1086.

and/or pedagogy (see Gibbs, 2001; Lowrie and Willmott, 2006; Lowrie, 2007; Lowrie, 2008; Lowrie and Willmott, 2009 for notable exceptions). Therefore there is considerable potential in terms of further exploring neoliberalism and consumption in the higher education context from a critical marketing perspective.

Third, research in services marketing in the context of higher education has been addressed by a number of previous authors e.g. (Zammuto et al., 1996; Angell et al., 2008), and customer satisfaction and student satisfaction are also popular topics for research in higher education (Athiyaman, 1997; Petruzzellis et al., 2006; Clemes et al., 2008), including the use of the popular SERVQUAL instrument (Arambewela \& Hall 2006). But, although there are researchers taking a more critical marketing stance towards services marketing (e.g. Skålén, 2009) there is much potential for further research in higher education marketing from this standpoint.

Fourth, Carter and Curry recommend that further research is needed in the field of higher education tuition fee sensitivity and this should explicitly take into account the impact of financial aid, including bursaries. There are surprisingly few papers which have studied price elasticity in the context of higher education (with the possible exception of (DeMoranville \& O'Donnell, 2001)). There are also considerable changes worldwide in terms of tuition fees and these rapid changes are a fertile source of research data for exploring price elasticity in addition to pricing strategies and funding mechanisms. 
Lowrie, A. \& Hemsley-Brown, J. (2011). This thing called marketisation (Editorial). Journal of Marketing Management, 27, 1081-1086.

Finally, authors of articles in this special issue also suggest that future research might need to utilise different research methods and sampling frames to take account of whether research findings would be supported using samples of students from different countries, and also from different backgrounds. For example Naidoo and $\mathrm{Wu}$ suggest that researchers need to consider using a broader sampling frame including universities from non-English speaking countries which are also increasingly active in international recruitment. Naidoo et al. indicate that there is a need in the future, to focus on longitudinal studies which examine the shaping of choice in relation to social class, ethnicity and diverse cultural traditions.

From the broader perspective, a really important question is how will the shifting parts of higher education move and come together to reformulate a sense of coherence under the characteristics of plurality, competition and contestation? Keeping in mind that a sense of coherence may stem from fragmentation, how can we develop an understanding of higher education fragmentation in the future? Segmentation of markets is likely to continue to grow in importance. How do we join up our thinking and our higher education to deliver what the plurality of communities want from it? How do we manage marketised thinking? Does it make sense to be either for or against the marketisation of higher education? The concept of higher education marketisation is akin to Foucault's 'historical ontology of ourselves' that determines who we are. There is no point in being for or against that which makes us what we are (Foucault, 1991 p.45). We need to reflect upon the higher education history that makes it as it is, and from there develop future directions. 
Lowrie, A. \& Hemsley-Brown, J. (2011). This thing called marketisation (Editorial). Journal of Marketing Management, 27, 1081-1086.

Our clear purpose for the special issue is to bring research on marketing and marketisation in higher education to the fore and gain attention from researchers in marketing, education, management and related social science fields. We hope that the articles in this edition will go some way towards raising the profile and status of research in the field of marketing and marketisation of higher education and we thank the general editors for all their support and help in this purpose.

This special issue of the Journal of Marketing Management is in part about building the reputation of marketing for higher education and as guest editors we are pleased to contribute. The contributions of authors in this edition are varied in terms of philosophical approach, methodology and implications and stand as a testament to the plurality of higher education. Nevertheless, we call for more and varied approaches and theory development, particularly in regard to ethics, improved samples, and longitudinal studies. The authors of these articles have 'survived' the rigors of the blind peer-review process from an initial submission of 54 manuscripts, and this commends their work. The special edition editors finally wish to thank authors for their diligence and offer the greatest of thanks and last word to the reviewers.

\section{Reference List}

Angell, R. J., Heffernan, T. W., \& Megicks, P. (2008). Service Quality in Post Graduate Education. Quality Assurance in Education, 16(3), 236-254. 
Lowrie, A. \& Hemsley-Brown, J. (2011). This thing called marketisation (Editorial). Journal of Marketing Management, 27, 1081-1086.

Arambewela, R., \& Hall, J. (2006). A Comparative Analysis of International Education Satisfaction using SERVQUAL. Journal of Services Research, 6, 141-163.

Athiyaman, A. (1997). Linking Student Satisfaction and Service Quality Perceptions: the case of university education. European Journal of Marketing, 31(7), 528-540.

Bakewell, C. J., \& Gibson-Sweet, M. F. (1998). Strategic Marketing in a Changing Environment: are the new UK universities in danger of being 'stuck in the middle? The International Journal of Educational Management, 12(3), 103-107.

Clemes, M. D., Gan, C., \& Kao, T. H. (2008). University Student Satisfaction: An Empirical Analysis. Journal of Marketing for Higher Education, 17(2), 292-325.

Conway, T., Mackay, S., \& Yorke, D. (1994). Strategic Planning in Higher Education: who are the customers? The International Journal of Educational Management, 8(6), 2936.

DeMoranville, C. W., \& O'Donnell, P. B. (2001). Price Elasticity of Per-Credit-Hour Tuition Charges and the Effects on Four-Year Graduation Rates. Journal of Marketing for Higher Education, 11(4), 29-49.

Foucault, M. (1991) What is Enlightenment. In P. Rabinow (ed.), The Foucault Reader: An Introduction to Foucault's Thought, London: Penguin.

Gibbs, P. (2001). Higher Education as a Market: a problem or a solution? Studies in Higher Education, 26(1), 85-94. 
Lowrie, A. \& Hemsley-Brown, J. (2011). This thing called marketisation (Editorial). Journal of Marketing Management, 27, 1081-1086.

Hemsley-Brown, J., and Oplatka, I. (2006). Universities in a competitive global marketplace: a systematic review of the literature on higher education marketing. International Journal of Public Sector Management, 19(4), 316-338.

Lowrie, A. (2007). Branding Higher Education: Equivalence and Difference in Developing University Identity. Journal of Business Research, 60(9), 990-999.

Lowrie, A. (2008). The Relevance of Aggression and the Aggression of Relevance: The Rise of the Accreditation Marketing Machine. International Journal of Educational Management, 22(4), 352-364.

Lowrie, A., \& Willmott, H. (2006). Marketing Higher Education: The Relevance of Promotion and the Promotion of Relevance. Social Epistemology, 20(3), 221-240.

Lowrie, A., \& Willmott, H. (2009). Accreditation Sickness in the Consumption of Business Education: The Vacuum in AACSB Standard Setting. Management Learning, 40(4), 411-420.

Ng, S., Lee, J., \& Soutar, G. (2007). Are Hofstede's and Scwartz's value frameworks congruent? International Marketing Review, 24(2), 164-180.

Niculescu, M. (2006). Strategic positioning in Romanian higher education. Journal of Organizational Change Management, 19(6), 725-737.

Petruzzellis, L., D’Uggento, A.M. and Romanazzi, S. (2006). Student satisfaction and quality of service in Italian universities. Managing Service Quality, 16(4), 349-364.

Scwartz, S. (1994). Beyond individualism/collectivism: new cultural dimensions of values. In U. Kim, H. C. Triandis, C. Kagitcibasi, S. C. Choi, and G. Yoon, (eds), 
Lowrie, A. \& Hemsley-Brown, J. (2011). This thing called marketisation (Editorial). Journal of Marketing Management, 27, 1081-1086.

Individualism and Collectivism: Theory, Method and Applications, Sage, London, (pp 85119)

Skålén, P. (2009). Service marketing and subjectivity: the shaping of customer-oriented employees. Journal of Marketing Management, 25(7/8), 795-809.

Tadajewski, M. (2010). Towards a history of critical marketing studies. Journal of Marketing Management, 26(9/10), 773-824.

Trim, P. J. (2003). Strategic marketing of further and higher educational institutions: partnership arrangements and centres of entrepreneurship. The International Journal of Educational Management, 17(2), 59-70.

Zammuto, R. F., Keaveney, S. M., \& O'Connor, E. J. (1996). Rethinking Student Services: Assessing and Improving Service Quality. Journal of Marketing for Higher Education, 7(1), 45-70. 